\title{
POVOS INDÍGENAS E ANTROPOLOGIA: NOVOS PARADIGMAS E DEMANDAS POLÍTICAS
}

\author{
ROSANI DE FÁTIMA FERNANDES ${ }^{1}$
}

UFPA

\section{Para início de conversa ...}

$\mathrm{Na}$ minha trajetória de vida pessoal, profissional, acadêmica e política, por diversas vezes me deparei com atitudes e posturas etnocêntricas, preconceituosas e racistas com relação às diferenças, sejam étnicas, culturais, linguísticas, de gênero, religiosas, entre outras. Durante mais de duas décadas trabalhei com educadores não indígenas nas aldeias onde morei, em regiões diferentes do Brasil: na Terra Indígena Xapecó, no hoje município de Ipuaçu, Estado de Santa Catarina, e na Aldeia Kyikatêjê, na Terra Indígena Mãe Maria, no hoje município de Bom Jesus do Tocantins, Estado do Pará. Nas duas comunidades, apesar de se tratar de povos diferentes, Kaingang e Gavião Kyikatêjê, e de estarem localizadas em regiões extremas do Brasil, Sul e Norte, constatei e vivenciei praticamente as mesmas dificuldades ${ }^{2}$.

Como indígena educadora, tive a possibilidade de participar de diversas reuniões, cursos de formação de professores indígenas e não indígenas, com profissionais de diversas áreas do conhecimento. De minha convivência pessoal e profissional nas duas comunidades, optei

\footnotetext{
1 Kaingang, pedagoga, doutoranda em Antropologia Social no Programa de Pós-Graduação em Antropologia (PPGA) da Universidade Federal do Pará (UFPA), sob orientação da Prof ${ }^{\mathrm{a}}$. Dr ${ }^{\mathrm{a}}$. Jane Felipe Beltrão. Bolsista Capes. E-mail: rosanifernandes2@hotmail.com.

${ }^{2}$ A razão dos "extremos" é devido ao meu casamento com um indígena da etnia Xerente, cuja família se relaciona há mais de trinta anos com os Gavião da Terra Indígena Maria, onde morei por quase uma década, trabalhando como assessora pedagógica na escola Tatakti Kyikatêjê, de 2004 a 2012.
} 
por trazer à baila nesta reflexão duas constatações que foram, e continuam sendo, importantes para a definição de parte de minhas escolhas profissionais, além de serem cruciais para minha tomada de posição política enquanto indígena educadora, pois são situações que ainda me causam, de alguma maneira, perplexidade e revolta: a primeira diz respeito às barreiras burocráticas e institucionais que sempre nos são colocadas quando requeremos direitos relacionados à educação escolar indígena, porque, com raras exceções, quase sempre temos como resposta as negativas das secretarias de educação, tanto municipais, quanto estaduais; a segunda é a constatação da falta de habilidade tanto dos educadores que atuam nas comunidades indígenas quanto dos técnicos das secretarias de educação para lidar com a diversidade, cujas consequências são, no mínimo, desastrosas.

Como pedagoga, preocupada com a qualidade dos trabalhos nas escolas em que trabalhei, desenvolvi algumas atividades com o objetivo de tentar minimizar os impactos negativos das posturas etnocêntricas de educadores que cotidianamente reproduzem relações de preconceito e discriminação, tanto na escola quanto nas comunidades, ora reforçando o ideal romântico do "bom selvagem", da "pureza" que deve ser intocada e preservada, ora expressando o preconceito que associa os povos indígenas à ideia de selvageria, bestialidade.

Dentre as atividades que realizei estão as oficinas sobre direitos indígenas com os educadores não indígenas, com o objetivo de desenvolver as diversas sensibilidades necessárias para o trabalho educacional, dentre as quais, a jurídica (GEERTZ, 1997), que é importante mecanismo para a realização de trabalhos educacionais comprometidos com a valorização das culturas indígenas. Foi nesse período que, mesmo realizando leituras, buscando sempre estar atualizada e conectada com as discussões sobre direitos indígenas, senti que precisava qualificar os debates.

Foi quando, motivada pela necessidade de ampliar as possibilidades de discussão a partir da experiência que vivenciávamos na comunidade, decidi pelo ingresso na pós-graduação. Apoiada pelas lideranças da comunidade, ingressei em 2007 no Mestrado em Direito do Programa de Pós-Graduação em Direito (PPGD) da Universidade Federal do Pará (UFPA), onde fui selecionada para uma das duas vagas 
reservadas para povos indígenas, que até então não haviam sido ocupadas. Passei pelo período de nivelamento, que era parte da política do programa para a permanência de mestrandos indígenas. Em 2008, devidamente matriculada, concorri à Bolsa Ford e fui selecionada, o que me possibilitou condições adequadas para permanência no curso.

$\mathrm{Na}$ minha dissertação ${ }^{3}$, construída em permanente diálogo com as lideranças da comunidade, discuti as dificuldades de efetivar educação escolar específica e diferenciada pelas inúmeras negativas institucionais e, principalmente, pela falta de conhecimento de causa da maioria dos técnicos das secretarias de educação. Também problematizei as possibilidades de trabalho escolar a partir das iniciativas da própria comunidade, mostrando como construímos, na Aldeia Kyikatêjê, uma proposta de educação a partir dos projetos étnicos e políticos, que tinham na escola a possibilidade de formação de lideranças políticas preparadas para responder aos novos desafios impostos pelas relações com o Estado brasileiro e a sociedade não indígena, o que requer princípios e metodologias diferenciadas de ensino e aprendizagem.

O mote central da discussão foi a metodologia empregada na elaboração de materiais didáticos via oficinas pedagógicas realizadas com professores e alunos da comunidade kyikatêjê no período de 2004 a 2007, onde os mesmos sistematizavam as vivências culturais no espaço escolar.

Desta feita, o mestrado em Direito me possibilitou o trânsito interdisciplinar necessário para atuar de forma qualificada nos trabalhos que já vinha realizando em educação escolar indígena, mas faltava na minha formação os referenciais antropológicos para que as atividades de formação de professores que realizo desde 1994 pudessem contar com os aportes teóricos e metodológicos da Antropologia.

Em 2011, depois de quase dois anos de conclusão do mestrado, por motivação pessoal, mas, sobretudo, pelo compromisso político com a melhoria da qualidade da educação escolar e pela necessidade de estabelecer diálogos, a partir dos referenciais da Antropologia, com os diversos profissionais que adentravam nossa comunidade, indigenistas, médicos, educadores, antropólogos, entre outros, me inscrevi para a

\footnotetext{
${ }^{3}$ Ver Fernandes (2010).
} 
seleção de doutorado no Programa de Pós-Graduação em Antropologia (PPGA) da UFPA, sendo aprovada.

Minha relação com os antropólogos é anterior ao meu contato com a Antropologia; fui orientada no mestrado pela antropóloga Jane Felipe Beltrão, que foi a pessoa que me convidou a prestar seleção do PPGD/UFPA. A conheci na Aldeia Kyikatêjê, no ano de 2004, na ocasião em que a mesma atendia ao convite das lideranças para assessorar a comunidade. Naquele primeiro encontro conversamos sobre o trabalho que estava em andamento na escola da aldeia sob minha coordenação e do meu desejo de cursar o mestrado e seguir nos estudos. A relação de confiança foi estabelecida e o projeto de mestrado foi construído com orientações via e-mail e telefone, pela distância da aldeia da capital do estado e pela impossibilidade de constantes deslocamentos. Minha aprovação no mestrado foi o primeiro passo para o início de novas formas de relação pessoal e profissional com a Antropologia. A convivência com a professora Jane era inspiradora, as atitudes politicamente comprometidas e eticamente responsáveis que presenciei cotidianamente por parte da mesma, a amizade que construímos e as parcerias na realização dos trabalhos foi decisiva para que eu ingressasse no doutorado em Antropologia, o que me colocou numa outra posição, diferente da que eu estava acostumada a vivenciar com antropólogos.

Até então, na condição de "nativa", fui "entrevistada" por antropólogos; outras vezes, participei de longas conversas e discussões sobre assuntos considerados estratégicos junto às lideranças das comunidades onde morei. Desse meu lugar de pertença, via sempre os antropólogos como pessoas e profissionais diferentes, principalmente com relação à postura diante das pessoas e dos acontecimentos, quase sempre mais atenciosos e cuidadosos nas intervenções, cautelosos nas formas de interagir com as lideranças, comportamentos consideradas incomuns às demais pessoas que costumam frequentar nossas comunidades.

Os antropólogos em geral me pareciam sempre mais preocupados em apreender conosco, com ouvidos e olhos sempre atentos aos detalhes, procurando interagir, aprender e participar das nossas atividades, mesmo quando a resposta era apenas um sorriso por não 
entender a brincadeira ou o silêncio por não compreender a conversa na língua materna. Observado nos mínimos detalhes, que eram depois comentados em algumas rodas de conversa, o antropólogo, na sua tarefa de observar e estudar o outro, é também "etnografado" nas suas minúcias: na forma de falar, de vestir, de andar, de sentar, de comer, no fato de aceitar ou não os alimentos oferecidos, de participar ou não das atividades para as quais é convidado... situações que vão determinar o estabelecimento, ou não, de relações de confiança com as pessoas da comunidade.

Atualmente, como antropóloga em formação e a partir dos referenciais da Pedagogia e do Direito, tenho a possibilidade de estabelecer diálogos interdisciplinares e empreender esforços no sentido de atuar de maneira crítica e politicamente situada tanto nas leituras e elaborações que realizo quanto nas intervenções propositivas na formação de professores indígenas e não indígenas e junto ao movimento indígena.

É certo que, cotidianamente, me deparo com novos desafios e é possível que tenha mais perguntas do que repostas para as questões que me são colocadas, tanto nas reflexões teóricas a partir da leitura dos clássicos da disciplina quanto nas produções que realizo no sentido de analisar nossa relação com a Antropologia, o que faço sempre baseada nas vivências individuais e coletivas, ainda que, até pouco tempo, posicionada do outro lado do espelho.

Nessa direção, Luciano indicou algumas possibilidades,

... [q]ue a disciplina ceda lugar a indisciplina
metodológica para dar lugar à diversidade, ao
inesperado, ao sonho humano, ao possível e sobretudo
à busca pelo desconhecido e pela liberdade de pensar,
de fazer e de viver; e estimular e valorizar o
espontâneo, o que não é conduzido, pelos dogmas
criados e impostos, para que o homem recupere sua
capacidade de pensar, inventar, criar, acertar e errar,
enfim ser humano e não máquina ou peça de uma
máquina pré-moldada, ou seja humano como humano
ou o índio como índio (LUCIANO, 2008, p. 10).

O recorte é do texto que Luciano, da etnia Baniwa, elaborou no esforço de estabelecer diálogos, em sendo indígena e antropólogo, sobre a percepção e relação que os povos indígenas vêm construindo 
com a Antropologia. Luciano propõe, entre outras possibilidades, a Antropologia Indígena como caminho para a descolonização do conhecimento acadêmico de base eurocêntrica. O texto na íntegra foi apresentado na plenária da $26^{a}$ Reunião Brasileira de Antropologia (RBA), realizada pela Associação Brasileira de Antropologia (ABA) em Porto Seguro, na Bahia, no ano de 2008.

À época cursando o doutorado, Luciano reflete as importantes contribuições da Antropologia, tanto na construção de instrumentos analíticos sobre a presença indígena no Brasil quanto como suporte para o Indigenismo brasileiro, especialmente nas relações de mediação e tradução estabelecidas entre os povos indígenas e o Estado. Sobre as contribuições da disciplina para sua vida pessoal, Luciano destaca que “... me permitiu conhecer um pouco do que os brancos pensam sobre os índios e como os índios se relacionam com esse modo de pensar dos brancos sobre eles" (2008, p. 03).

Hoje professor da Universidade Federal do Amazonas (UFAM), Luciano é referência nas elaborações sobre educação escolar indígena no Brasil, tendo atuado no Ministério da Educação (MEC) por longo período, onde protagonizou a implantação dos Territórios Etnoeducacionais. O destaque não se deve somente pelo fato de Luciano realizar discussões sobre a relação da Antropologia com povos indígenas, mas por ser um dos poucos indígenas a assumir uma cadeira como docente numa universidade federal brasileira, e, da mesma forma, ocupar posição relevante no planejamento de políticas públicas em educação escolar para povos indígenas junto ao MEC.

Como indígena, antropólogo e liderança no movimento indígena nacional, Luciano dimensiona a importância da presença indígena nas universidades, tanto na inserção nos cursos de graduação e pósgraduação quanto na docência no ensino superior, caminho ainda a ser percorrido e conquistado, pois o espaço acadêmico, assim como a maioria das instituições públicas brasileiras, ainda se apresenta hostil às diferenças.

Nesse sentido, em resposta às minhas próprias inquietações, concordando com Luciano e considerando a necessidade de ampliação das discussões acerca da relação dos povos indígenas com a Antropologia no Brasil, bem como levando em consideração os poucos 
trabalhos elaborados por indígenas na área em tela, especialmente sobre o recorte da temática proposta, tenho como objetivo, neste ensaio, contribuir para os debates acerca das possibilidades de apropriação dos referenciais epistemológicos da disciplina pelos povos indígenas, para estabelecer diálogos menos assimétricos com 0 chamado "mundo dos brancos".

Portanto, a tarefa é parte dos esforços individuais e coletivos no sentido de protagonizar novas elaborações acadêmicas a partir das percepções e diálogos daqueles que, por longo período da história da Antropologia, foram tomados como "objetos de estudo", ou, ainda, como "informantes" na elaboração de trabalhos.

\section{Inclusão e protagonismo indígena: o caminho da descolonização}

O protagonismo nas elaborações acadêmicas, assim como no estabelecimento de diálogos menos assimétricos com Estado brasileiro, vem cada vez mais sendo demandado pelas coletividades indígenas, e constitui parte da agenda de luta para construção da autonomia e da autodeterminação reivindicada pelas lideranças, comunidades e organizações indígenas que compõem o movimento indígena nacional. No contexto das lutas e enfrentamentos históricos e cotidianos, a inserção de lideranças políticas indígenas no chamado "mundo dos brancos" é uma das possibilidades para a formação de mediadores que possam atuar no registro e elaboração das histórias indígenas, ao mesmo tempo em que estejam aptos a fazer a "a ponte" como tradutores do mundo não indígena a partir da apropriação de novos conhecimentos.

A crescente demanda pela inserção indígena nas mais diversas áreas do conhecimento, com atenção especial àquelas consideradas prioritárias, como saúde, educação, direito, entre outras, também é parte das estratégias elaboradas pelos povos indígenas para o exercício do protagonismo nas relações com o Estado brasileiro, que devem ser pautadas em novos paradigmas, onde os indígenas, enquanto sujeitos plenos de direito e conhecimento, sejam também sujeitos na elaboração de suas próprias histórias, situando, desta feita, "os brancos" e suas 
instituições nas cosmologias e sentidos que são próprios de cada povo indígena, produzindo novas relações políticas, históricas e cosmológicas com vistas à superação do estereótipo de "vítimas da história" (CARNEIRO DA CUNHA, 2002).

A "domesticação" dos espaços hegemônica e historicamente constituídos de forma hostil às diferenças étnicas é parte das novas demandas dos movimentos indígenas; portanto, se insere no ideário coletivo de luta que se instaurou principalmente a partir da década de 70 , quando os movimentos indígenas intensificam as reivindicações para o respeito às diferenças e a promoção da autonomia como forma de superação da tutela instituída historicamente no país, o que, ainda hoje, se constitui obstáculo para a autodeterminação indígena. Apesar de superada no plano legal, a ideia de inferioridade e submissão indígena ainda está arraigada nas relações sociais e institucionais no Brasil, que relegam às minorias posições de subalternidade e inferioridade (SPIVAK, 2010).

Com vistas ao fortalecimento da autonomia, as comunidades indígenas elaboram estratégias de enfrentamento a inúmeras formas de exclusão e preconceito, rejeitando a condição de subalternidade e exercendo o protagonismo como instrumento de inclusão.

A crescente inserção indígena nas universidades é exemplo destas novas formas de relação em construção, a busca por outros conhecimentos tem levado muitos parentes indígenas aos bancos universitários. Luciano, Oliveira e Barroso-Hoffmann (2010) explicam que são mais de 6.000 indígenas estudantes nos cursos de ensino superior; destes, pelos menos 100 estão nos cursos de pós-graduação. Os números ainda são tímidos, mas vêm aumentando significativamente, especialmente nos cursos de graduação, via conquistas dos movimentos indígenas, como a Lei 12.711, a Lei de Cotas ${ }^{4}$, o Programa Bolsa Permanência, entre outros que visam promover o acesso e a permanência nos cursos de graduação.

O ingresso no ensino superior é parte do ideário de luta das comunidades e organizações indígenas que, por meio das lideranças políticas, estabelecem novas formas de diálogos para o domínio dos códigos da sociedade não indígena, pois conhecer os trâmites legais e

\footnotetext{
${ }^{4}$ Disponível em: http://portal.mec.gov.br/cotas/perguntas-frequentes.html. Acesso em 27 de nov. de 2013.
} 
transitar nos mais diversos espaços institucionais não indígenas é um dos principais desafios enfrentados pelas comunidades indígenas na atualidade.

A tarefa de "etnografar o branco" (ALBERT e RAMOS, 2002) tem sido cada vez mais requerida pelas comunidades indígenas, que concebem a apropriação dos referenciais epistemológicos ocidentais como instrumentais importantes para a defesa e garantia de direitos, conquistados no âmbito nacional e internacional via organização e reivindicação indígena (ARAÚJO, 2006), principalmente no que se refere às terras indígenas, que são constantemente ameaçadas e invadidas por empreendimentos econômicos, na maioria dos casos perpetrados pelo Estado brasileiro, via construção de rodovias, hidrelétricas, ferrovias, linhas de transmissão de energia, entre outros que impactam negativamente as terras, causando danos muitas vezes irreversíveis e colocando "em cheque" a possibilidade de futuro das próximas gerações.

No que tange à histórica relação dos povos indígenas com o Estado brasileiro, sem dúvida a Antropologia ocupa lugar de destaque, tanto no que se refere à mediação com as comunidades indígenas quanto na colaboração e atuação na garantia do reconhecimento e defesa de direitos indígenas. Entendidos como tradutores ou mediadores, os antropólogos realizam estudos, elaboram laudos, emitem pareceres, ao mesmo tempo em que são entendidos pelas comunidades indígenas como potenciais aliados e colaboradores pela possibilidade de trânsito entre o mundo indígena e não indígena.

Mas é fato que, na medida em que os próprios indígenas se apropriam dos referenciais teóricos e metodológicos das diversas áreas do conhecimento, têm, diante de si, a possibilidade de realização de releituras dos cânones considerados clássicos e, desta feita, passam a erigir novos olhares a partir do lugar de pertença que fornece as lentes pelas quais leem o mundo. Portanto, ser indígena e estar na academia, em especial no curso de Antropologia, é a possibilidade de aproximação dos referenciais que orientaram e orientam as elaborações antropológicas. É certo que a discussão em tela carece de maiores aprofundamentos, mas meu esforço está em, a partir do meu lugar de pertença, propor reflexões sobre o assunto. 


\section{A Antropologia e as novas demandas indígenas}

A Antropologia ${ }^{5}$ começa a se consolidar academicamente no início da segunda metade do século XIX, quando são realizados os estudos pioneiros que se estabelecem como referenciais clássicos da disciplina. Para Pacheco de Oliveira (2004), os estudos pioneiros, emoldurados no cenário colonial do encontro entre o antropólogo e o nativo, eram marcados pela visão unilateral: o "de fora", que percebe e objetiva o "outro", classificando e enquadrando o nativo na lógica ocidental eurocêntrica de produção de conhecimento.

Desde então muita coisa mudou, o exotismo e o estranhamento que marcavam as primeiras elaborações antropológicas foram aos poucos cedendo espaço às novas metodologias, as técnicas iniciais foram revistas e adaptadas para atender novas finalidades e demandas, o que implica no diálogo com outras disciplinas para elaboração de novos paradigmas que deem conta da pluralidade das novas formas de produção e elaboração cultural (PACHECO DE OLIVEIRA, 2004).

A imagem tradicional do antropólogo malinowiskiano que convive por longos períodos nas aldeias para a realização do clássico trabalho de campo passou por inúmeras metamorfoses. A presença de antropólogos nas comunidades, assim como as possibilidades e condições de realização dos trabalhos de campo, são ressignificadas, reelaboradas e redefinidas a partir das percepções de cada povo. Atualmente são inúmeras as possibilidades de elaborações colaborativas, porque os antropólogos, com raras exceções, são considerados potenciais aliados políticos da causa indígena. Uma vez estabelecidas relações de confiança, os profissionais passam a ser requisitados pelas comunidades para diversas atividades, que nem sempre podem estar vinculadas diretamente aos interesses de estudo, podendo ser as mais variadas possíveis, indo desde a intervenção e mediação em assuntos específicos da comunidade até o encaminhamento e atuação em assuntos nas diversas esferas de poder e

\footnotetext{
5 Ver também: Fernandes (1975), Pina Cabral (2004), Trajano Filho e Ribeiro (2004), Corrêa (2003 e 2013) e Salzano (2009).
} 
instituições com as quais os povos indígenas mantêm alguma forma de relação.

Cada vez mais as comunidades indígenas tomam para si a decisão sobre quem trabalha, realiza pesquisas ou mesmo pode ter acesso às aldeias. A superação da tutela via protagonismo indígena tem gradativamente retirado das mãos da Fundação Nacional do Índio (Funai) a suposta atribuição de emissão de autorizações sobre o ingresso de pessoas e realização de atividades nas aldeias indígenas.

No caso dos antropólogos, tomados como parceiros de luta, representam a possibilidade de compreensão "de perto" das questões melindrosas com as quais os povos indígenas se deparam e que exigem, por exemplo, a realização de estudos ou laudos antropológicos. Nesse sentido, a partir da releitura da presença dos antropólogos nas aldeias, os trabalhos a serem realizados passam a ser meticulosamente negociados a partir de critérios próprios de cada povo indígena. As pesquisas antropológicas são negociadas, mesmo quando 0 antropólogo se apresenta com o objetivo de realizar pesquisas vinculadas aos interesses do Estado.

Quando os antropólogos se apresentam vinculados às universidades, a relação pode ser outra, podendo significar a possibilidade de realização de alianças diversas e duradouras, mediadas pela possibilidade de realização de outras parcerias, como a mediação no ingresso de indígenas estudantes nos cursos universitários.

Para Pacheco de Oliveira (2004), tanto a entrada quanto a permanência destes profissionais nas comunidades, bem como a realização dos trabalhos, é negociada, os objetivos são ajustados e, em alguns casos, adaptados aos objetivos das comunidades, que requerem a participação em todas as etapas da pesquisa, além do "retorno", que pode ser a produção de documentos requisitados pelas comunidades, ou mesmo a participação na intermediação de questões diversas junto aos órgãos governamentais e/ou não governamentais, principalmente no estabelecimento de diálogos com profissionais de outras áreas, tal como acontece na elaboração dos laudos antropológicos.

[H]oje, os líderes indígenas já discutem diretamente com os antropólogos as compensações exigidas que podem incluir: atuar em programas de saúde, colaborar 
nas escolas locais; escrever laudos e relatórios para organismos públicos, assumir responsabilidades na identificação de terras, na elaboração de programas de desenvolvimento, na gestão de conflitos e na preparação de programas de recuperação lingüística, cultural ou documental (PACHECO DE OLIVEIRA, 2004, p. 19 , sic).

Nesse sentido, a negociação passou a orientar as relações entre comunidades e antropólogos, que são acionados sempre que necessário, principalmente no assessoramento de questões relacionadas à terra, saúde, educação... tais negociações, baseadas em relações de confiança, são definidas a partir de parâmetros específicos elaborados de acordo com o entendimento de cada povo indígena, que "cobra" resultados, participa ativamente das pesquisas, avalia o que é produzido e como é produzido, controlando os resultados, faz críticas e participa da elaboração do trabalho como sujeito ativo do processo (PACHECO DE OLIVEIRA, 2004).

De "objeto de estudo" as comunidades indígenas passam a sujeitos na elaboração de conhecimento sobre si mesmas, se apropriando dos referenciais ocidentais para compreender os processos históricos de dominação, subordinação e assimilação, reagindo e reescrevendo as histórias a partir de epistemologias e cosmovisões próprias, desfiando a academia à revisão das posturas historicamente europeizadas, elitizadas e ocidentalizadas ${ }^{6}$.

Uma das grandes discussões dos movimentos indígenas no que se refere à inserção de estudantes indígenas nos cursos de graduação e pós-graduação está na dificuldade em romper as estruturas hostis das instituições de ensino, heranças coloniais que permanecem arraigadas nas relações institucionais e que, em muitos casos, violentam os indígenas estudantes via manifestações cotidianas que rechaçam e desconsideram as diversidades, as tradições e as múltiplas formas de produção de conhecimento, historicamente excluídas do espaço

\footnotetext{
${ }^{6}$ Para Castro Faria (2006, p. 17), “... a antropologia foi um campo de conhecimento estruturado numa época em que as ciências biológicas praticamente constituíam a abordagem hegemônica", quando a anatomia era considerada ciência de destaque nas academias e nas universidades. A antropologia no Brasil, alicerçada como ciência biológica, preocupa-se com as diferenças entre os grupos humanos, que são explicadas biologicamente, os povos são classificados tomando como base o modelo eurocêntrico de evolução e de civilização forjados a partir dos modelos deterministas raciais, pois "[o] modelo racial servia para explicar as diferenças e hierarquias...” (SCHWARCZ, 1993, p. 85).
} 
universitário.

$\mathrm{Na}$ Universidade Federal do Pará, por exemplo, estudantes dos cursos da área de saúde, em especial do curso de Medicina, denunciam a intolerância de alguns docentes que não consideram as diferenças étnicas e culturais. São manifestações de preconceito e discriminação que reproduzem as relações de exclusão e colonialismo, que concebe, ainda, a universidade como "privilégio" de elites "brancas". A violência e o preconceito institucional podem ser manifestos, por exemplo, na não valorização das produções acadêmicas indígenas, ou ainda na atribuição de menor status a estas, consideradas menores, inferiores. Para Luciano, Oliveira e Barrosa-Hoffmann (2010), há pouca valorização das produções indígenas na academia, uma vez que “... já foram produzidas pelo menos 40 dissertações de mestrado e cinco teses de doutorado. No entanto, essas teses e dissertações não foram até hoje publicadas e divulgadas, mesmo sendo as pioneiras no Brasil ..." (LUCIANO, OLIVEIRA e BARROSO-HOFFMANN, 2010, p. 07).

Além da pouca valorização dos trabalhos indígenas na academia, o não diálogo com as epistemologias indígenas, pautado sobretudo no eurocentrismo, também se constitui barreira para a acolhida de conhecimentos indígenas diversos nos espaços hegemônicos de poder e saber. Para Quijano,

[a] elaboração intelectual do processo de modernidade produziu uma perspectiva de conhecimento e um modo de produzir conhecimento que demonstram o caráter do padrão mundial de poder: colonial/moderno, capitalista e eurocentrado (QUIJANO, 2005, p. 19).

É fato que as instituições de ensino superior não estão preparadas para lidar com as demandas indígenas, com as diferenças, nem mesmo com as formas diversas de produção de etnoconhecimentos. Apesar da implementação de políticas e programas de acesso e permanência de indígenas estudantes nas universidades, verifica-se que ainda há poucos trabalhos que contemplem as especificidades epistemológicas indígenas. Há que se considerar também a grande diversidade de povos indígenas no Brasil e a multiplicidade de expressões culturais que 
representam os mais de $300^{7}$ povos indígenas no Brasil hoje, o que torna ainda maior o desafio das instituições de ensino para a superação do eurocentrismo que marcou por longa data as produções acadêmicas no Brasil.

Quijano define eurocentrismo como sendo,

... uma específica racionalidade ou perspectiva de conhecimento que se torna mundialmente hegemônica colonizando e sobrepondo-se a todas as demais, prévias ou diferentes, e a seus respectivos saberes concretos, tanto na Europa como no resto do mundo (QUIJANO, 2005, p. 19).

A superação da colonização técnico-científica discutida por Quijano (2005) é também requerida pelos indígenas intelectuais e pelos movimentos indígenas, conforme problematiza Luciano (2008) quando afirma que é necessária a elaboração de novas metodologias capazes de implementar diálogos interculturais efetivos, tanto na produção quanto na transmissão de conhecimentos, como forma de superação das diversas formas de colonização, dentre estas, o Colonialismo Interno, categoria discutida por Cardoso de Oliveira (1998), que afirma que as relações entre a Europa e a América Latina foram marcadas pelo binômio colonialismo e pelo colonialismo interno, “... o primeiro próprio do mundo europeu; o segundo, próprio do mundo latino-americano" (CARDOSO DE OLIVEIRA, 1998, p. 41). O colonialismo interno, segundo a acepção de Cardoso de Oliveira (1998), retém parte das características das relações coloniais, que implicam em dominação política e exploração econômica do colonizador sobre o colonizado, reproduzindo mecanismos de dominação e exclusão. O antropólogo, nesta perspectiva, “... acaba por ocupar um lugar como profissional da disciplina na etnia dominante ..." (CARDOSO DE OLIVEIRA, 1998, p. 42).

\footnotetext{
${ }^{7}$ Segundo dados do Censo 2010 do Instituto Brasileiro de Geografia e Estatística (IBGE), a população indígena no Brasil é de 817.963 pessoas, vivendo em "áreas urbanas" e "rurais", o que significa um crescimento significativo com relação ao censo realizado em 1991, quando o total era de 294.131, e de 2000, quando o número de indígenas era "oficialmente" 734.127. De 1991 a 2010 o número praticamente triplicou, fato que se deve principalmente às mudanças na própria conjuntura legal do Estado brasileiro, fruto das mobilizações e reivindicações dos movimentos indígenas, que, pela primeira vez, na Constituição Federal de 1988, reconheceu o direito de continuidade das memórias, histórias e identidades indígenas. As informações podem ser acessadas no site do IBGE: http://indigenas.ibge.gov.br/graficos-etabelas-2. Acesso em 20 de nov. de 2013.
} 
Para Cardoso de Oliveira, o desconforto somente é diluído, ou ainda minimizado, se os antropólogos atuarem como intérpretes e defensores dos povos indígenas, incorporando, desta feita, a dimensão política, tanto em sua prática, comportamento e produção teórica. Cardoso de Oliveira (1998) chama atenção para diferença entre o antropólogo europeu e o antropólogo latino-americano, para o último, cidadania e profissão são "faces de uma mesma moeda" (CARDOSO DE OLIVEIRA, 1998, p. 43). O antropólogo latino-americano tem em sua especificidade profissional a prática e a dimensão teórica do indigenismo, que esteve presente desde o início da disciplina. No Brasil, o compromisso com a causa indígena marcou a disciplina especialmente a partir dos anos 30 do século passado. Desta feita, o indigenismo, na perspectiva do autor, constitui importante perspectiva na construção da Antropologia no Brasil.

A Antropologia no Brasil em especial avançou muito nessa direção, estabelecendo diálogos interculturais que resultaram em várias produções importantes sobre direitos indígenas e políticas indigenistas, como as realizadas por Carneiro da Cunha (1987 e 1992), Santos (1982 e 1989), Souza Lima (1995), Souza Lima (2002), Pacheco de Oliveira (2004), entre outros que são referenciais na luta pela efetivação de direitos indígenas acionados tanto por indígenas quanto por não indígenas para, entre outras possibilidades, discutir a relação do Estado brasileiro com os povos indígenas e em muitos casos denunciar violações e violências perpetradas contra as coletividades indígenas. Para Souza Lima, este movimento de articulação em prol dos direitos indígenas deveria ser ampliado para outras esferas,

[c]oncentro-me na antropologia produzida no Brasil porque, pela via tanto da crítica quanto da intervenção, ela vem sendo um articulador fundamental nas inovações das políticas e Estado para as populações indígenas.Valeria a pena pensar algo semelhante para as esferas do direito, dos saberes médicos e das ciências voltadas para o meio ambiente (SOUZA LIMA, 2002, p. 87).

Souza Lima (2002) também destaca as importantes e valorosas contribuições a partir de experiências de antropólogos vinculados ou não aos aparelhos de governo e que têm desenvolvido práticas 
inovadoras nas relações com as sociedades indígenas. Muitas destas novas elaborações se devem às percepções sobre o papel político e ético dos antropólogos junto aos povos indígenas, a partir de perspectivas plurais e metodologias de pesquisa participativas que anunciam novas formas de produção etnográfica.

\section{Por uma etnografia polifônica}

Para Clifford (1998), o modo clássico de fazer Antropologia, baseado na autoridade etnográfica do autor que escreve "sobre" e não "com", vem sendo questionado pelos pós-modernos. Nesse sentido, urge o reconhecimento das lacunas e equívocos cometidos por posturas científicas etnocêntricas para novas possibilidades metodológicas, mais adequadas à multiplicidade e diversidade dos povos como sujeitos de conhecimento.

... o Ocidente não pode mais se apresentar como o único provedor de conhecimento antropológico sobre o outro, tornou-se necessário imaginar um mundo de etnografia generalizada. Com a expansão da comunicação e da influência intercultural, as pessoas interpretam os outros, e a si mesmas, numa desnorteante diversidade de idiomas (CLIFFORD, 1998, p. 19).

Para Clifford (1998), tornou-se crucial para os povos formar imagens uns dos outros, de maneira que sejam compreensíveis as interconexões das relações de poder e de conhecimento estabelecidas a partir de relações históricas. Para o autor, a linguagem é atravessada por intenções e sotaques, “... [a]s palavras da escrita etnográfica, portanto, não podem ser pensadas como monológicas, como a legítima declaração sobre, ou a interpretação de uma realidade abstraída e textualizada" (CLIFFORD, 1998, p. 44). A linguagem, nesse sentido, é atravessada por subjetividades, e o etnógrafo está imerso numa teia de relações intersubjetivas em campos de poder, portanto, não há nenhuma posição neutra em se tratando de posicionamentos discursivos (CLIFFORD, 1998, p. 45).

A etnografia consiste “... num processo de diálogo em que os 
interlocutores negociam ativamente uma visão compartilhada de realidade" (CLIFFORD, 1998, p. 45), ou seja, é uma interpretação do ponto de vista do nativo, então a experiência da pesquisa é sempre "uma negociação em andamento" (CLIFFORD, 1998, p. 47). Isto porque "[a] escrita etnográfica atual está procurando novos meios de representar adequadamente a autoridade dos informantes" (CLIFFORD, 1998, p. 48).

A provocação está colocada pelos pós-modernos, que, a partir de alguns eventos, como a publicação dos diários de Malinowski, advogam pela revisão dos cânones clássicos da disciplina, que deve estar aberta às multivocalidades na produção textual. Para Clifford, "os atuais estilos de descrição cultural são historicamente limitados e estão vivendo importantes metamorfoses." (1998, p. 20)

Clifford prossegue afirmando que a ciência etnográfica não pode ser realizada desconectada de um debate político-epistemológico mais geral sobre a escrita e a representação da alteridade.

[É] mais do que nunca crucial para os diferentes povos formar imagens complexas e concretas dos outros, assim como das relações de poder e de conhecimento que as conectam: mas nenhum método científico soberano ou instância ética pode garantir a verdade de tais imagens. Elas são elaboradas - a crítica dos modos de representação colonial pelo menos demonstrou bem isso - a partir das relações históricas específicas de dominação e de diálogo (CLIFFORD, 1998, p. 18).

$\mathrm{Na}$ esteira das mudanças, novas possibilidades de leitura e produção textual estão sendo ensaiadas, ressignificando o papel dos povos indígenas nas elaborações, que, imbuídos do discurso que reivindica o protagonismo e o controle social sobre tudo que thes diz respeito, especialmente a partir dos marcos constitucionais e das conquistas assinaladas pela Convenção n. 169 da Organização Internacional do Trabalho (OIT) e pela Declaração Universal dos Direitos dos Povos Indígenas da Organização das Nações Unidas (ONU), requerem participação direta e controle de todas as ações que lhes digam respeito, produzindo inclusive novos marcos para a própria Antropologia. 
Manuela Carneiro da Cunha (1992) explica que as sociedades indígenas elaboram, a sua maneira, formas diferentes de compreender as relações históricas com os "brancos" e significam (e ressignificam) a partir de suas cosmovisões o contato com os não indígenas, reivindicando para si o papel de sujeitos e protagonistas no processo, não como vítimas, como comumente são concebidos. Porque enquanto a Antropologia estava preocupada com as suas formas de entender e conceber o outro não se dava conta de que também era questionada e ressignificada por esses "outros". Para Carneiro da Cunha (1992), durante muito tempo imperou no Brasil a noção de que os indígenas foram vítimas históricas de um sistema mundial, “... vítimas de uma política e de práticas que lhes eram externas e que os destruíram" (CARNEIRO DA CUNHA, 1992, p. 17).

Ao que acrescenta,

[e]ssa visão, além de seu fundamento moral, tinha outro, teórico: é que a história, movida pela metrópole, pelo capital, só teria nexo em seu epicentro. A periferia da capital era também o lixo da história. O resultado paradoxal dessa postura 'politicamente correta' foi somar a eliminação física e étnica dos índios sua eliminação como sujeitos históricos (CARNEIRO DA CUNHA, 1992, p. 17).

A contraposição dessa visão eurocentrista da história, que trata os povos indígenas como periféricos na produção da historiografia oficial, é a afirmação de que os povos indígenas são agentes de suas histórias e não vítimas, pois interferem, participam, decidem a partir de uma consciência histórica, de maneira que cada povo indígena significa o contato e o "homem branco" a partir das cosmologias e histórias indígenas, ou seja, a partir da ação e da vontade indígena no fazer história (CARNEIRO DA CUNHA, 1992, p. 18).

Para Sahlins, "[a] história é ordenada culturalmente de diferentes modos nas diversas sociedades, de acordo com os esquemas de significação das coisas" (1997, p. 7). A cultura é modificada historicamente na ação. Tomando a premissa de Sahlins (1997), é possível afirmar que não há uma história, mas histórias, elaboradas na diversidade e dinamicidade dos povos e culturas. Barth (2000) entende que um evento cultural é vivenciado de formas diferentes pelas pessoas, 
que produzem diversas formas de relação e interpretação do mesmo.

Os atores estão posicionados diferentemente, e, portanto, não há um interlocutor preferencial ou privilegiado que dê conta de todos os aspectos de um mesmo acontecimento ou fato, enquanto a cultura reproduz diferenças sobre as pessoas e não as reduz. A pesquisa nesse sentido é uma interpretação, uma leitura possível, porque as culturas são heterogêneas, fraturadas, permeadas por incertezas, incoerências, espaços possíveis. As pessoas vivem e experienciam a cultura de maneiras diferentes, por meio da interação, porque as fronteiras são fluídas e fraturadas (BARTH, 2000).

Desta feita, não há mais espaço para a "autoridade experiencial inquestionável do autor", que, na concepção de autoridade polifônica proposta por Clifford (1998), é diluída pelas muitas vozes no texto, porque tudo está interconectado. Não é mais a experiência individual relatada no texto que confere veracidade e objetividade: "eu vi", "eu estive lá", "posso falar porque estive lá", a experiência cede lugar à produção com e pelos os sujeitos. Para Clifford (1998), todas as vozes falam no texto, de forma intersubjetiva, não coercitiva, portanto, não pode mais ser "limpo" (higienizado) para encenar uma autoridade, mas deve apresentar as incoerências e os dilemas inerentes ao trabalho polifônico.

\section{Kaingang entre os Tembé Tenetehara de Santa Maria do Pará}

Conforme expliquei no início do trabalho, tenho buscado formação interdisciplinar como forma elaborar respostas para os desafios pessoais, profissionais e políticos que enfrento em sendo indígena educadora e militante em direitos indígenas. Minhas vivências e experiências pessoais e profissionais, intra e interculturais, me conduziram por diferentes caminhos, em alguns casos mediados pela minha condição de "parente" que compartilha as mesmas lutas. Hoje, cursando o doutorado em Antropologia, me vejo novamente diante de um novo desafio: elaborar o trabalho de tese com os parentes Tembé Tenetehara de Santa Maria do Pará, povo Tupi que há cerca de uma década iniciou o processo de retomada da terra de ocupação tradicional 
e de reafirmação identitária, depois de mais de um século de imposição cultural e linguística que os silenciou, principalmente pelas investidas do Estado brasileiro via política educacional escolarizada 8 .

Os Tembé Tenetehara ${ }^{9}$ pertencem ao tronco linguístico TupiGuarani, e, conforme o linguista Boudin (1978), a autodenominação Tenetehara significa "gente", "índio verdadeiro", enquanto Timbé, que é sua variante, provavelmente foi designada pelos regionais e significa "nariz chato". Registros de Wagley e Galvão (1961) informam que os Tenetehara migraram da região do Pindaré em direção aos rios Guamá, Gurupi e Capim, por volta de 1850, as aldeias tenetehara se estendiam de Barra do Corda, no Rio Mearim, no hoje Estado do Maranhão, até os rios Gurupi, Capim e Guamá, na região nordeste do Estado do Pará. Por volta da década de 60 , a população tenetehara do Guamá e Capim estava estimada entre 350 e 450 pessoas.

Dentre as causas da violenta redução populacional estão principalmente o contágio de doenças, como a gripe e o sarampo, advindas principalmente do "confinamento" nos aldeamentos 10 e do contato com os não indígenas, realizado por meio dos regatões que percorriam os rios com vistas à aquisição e troca de mercadorias, conforme assinala Ricardo:

\footnotetext{
${ }^{8}$ Com relação à história da Antropologia no Brasil e o período em questão, Melatti (2007) informa que no século XIX os corpos são normatizados, descritos e concebidos pela anatomia que procura identificar os males que impedem o progresso da sociedade brasileira, enquanto o pressuposto da degeneração das raças domina as discussões antropológicas no que pode ser chamado de primeiro momento da Antropologia no Brasil, por meio de estreito diálogo com a Biologia, a Medicina e o Direito, que por meio de estudos sistemáticos associam características antropométricas a certas qualidades e defeitos morais que estariam associados à ideia de raça, gerando classificações em raças inferiores e superiores. No campo políticoideológico, a superação da degeneração era pensada como estratégica para a conformação de uma nação nos moldes europeus, define a Antropologia até os anos 30 do século XX. Texto disponível em: http://www.dan.unb.br/corpo-docente. Acesso em 03 de jan. de 2014.

${ }^{9}$ De acordo com o linguista Max Boudin (1978), os Tembé constituem o ramo ocidental dos Tenetehara. Os Guajajara são o grupo oriental. Fonte: http://pib.socioambiental.org/pt/povo/tembe/1021. Acesso em 28 de set. de 2014. Para mais informações sobre os Tenetehara, consultar: Gomes (2002).

${ }^{10}$ A tática de aldear os indígenas distantes de suas terras foi realizada no Brasil desde o período colonial, quando os jesuítas se ocuparam com a catequização e civilização dos "gentios". A aldeia era o local de "amansamento" daqueles que eram considerados "selvagens". Uma vez amansados, passariam a auxiliar na busca dos que eram considerados "brabos" e que, de alguma forma, resistiam ao contato. Os aldeamentos garantiam a ocupação territorial porque liberavam os territórios da presença indígena, além disso, asseguravam mão de obra para os não indígenas e para a própria sustentação do aldeamento. $\mathrm{O}$ trabalho de catequese, por sua vez, era a possibilidade de rápida expansão do sistema colonial e se dava pela adoção de intérpretes indígenas para o ensino do evangelho, da escrita e da leitura às crianças (PACHECO DE OLIVEIRA e ROCHA FREIRE, 2006). A prática da catequese em sistema de aldeamentos pelos missionários é atualizada no século XIX, mantendo alguns dos princípios, como enclausuramento, adoção de intérpretes, ensino da escrita e da leitura e trabalhos agrícolas e manuais.
} 
[n]o século XIX, já no Gurupi, Guamá e Capim, os Tenetehara, então chamados de Tembé, foram submetidos à política de aldeamentos das Diretorias Parciais criadas pelo Regimento de 1845. Nessa ocasião, desde há muito obrigados a diversificar sua economia para produzir artigos de troca em conseqüência do contato com os regatões... (RICARDO, 1985, p. 182).

Somente por volta da década de 70 do século $X X$ é que houve a retomada do crescimento demográfico, apesar de lento. Atualmente, os Tembé Tenetehara se localizam em aldeias situadas no Estado do Pará, enquanto os Guajajara, que são o ramo Tenetehara oriental, estão localizados no Estado do Maranhão.

Depois de quase meio século de retomada do crescimento demográfico, o que foi possível, sobretudo, pela elaboração de estratégias próprias de resistência, os Tenetehara, Tembé e Guajajara encontram-se hoje entre os povos indígenas do Brasil com maior população. Conforme informações do Censo Demográfico de 2010 , do Instituto Brasileiro de Geografia e Estatística (IBGE), somam 24.428 pessoas, das quais 4.473 vivem fora das terras indígenas. No Pará, atualmente, são cinco ${ }^{11}$ as terras indígenas tembé tenetehara.

Os Tembé Tenetehara de Santa Maria do Pará, estão localizados hoje nas aldeias Jeju e Areal, localizadas nos limites do Município de Santa Maria do Pará12 e, conforme narram os próprios Tembé, o município avançou sobre o território de ocupação tradicional, expulsando-os, ou seja, a cidade chegou até eles. Distante cerca de 100

\footnotetext{
${ }^{11}$ Sendo: (1) Terra Indígena do Alto Rio Guamá (TIARG), com área oficial de 279.897 hectares e uma população de 1.425 pessoas; (2) Terra Indígena Tembé, localizada no município de Tomé-açu e que possui área de 1.075 hectares, população de 60 pessoas e encontra-se "Regularizada"; (3) Terra Indígena Turé-Mariquita e (4) Reserva Indígena Turé-Mariquita II, ambas localizadas no município de Tomé-Açu, a primeira com área de 146.97 hectares, juridicamente regularizada como "terra tradicionalmente ocupada" e que conta com população de 40 pessoas. A Reserva Indígena Turé-Mariquita II possui área de 593.55 hectares e enquadra-se na modalidade de Reserva Indígena, com situação jurídica constando como "Encaminhada" nos registros da Fundação Nacional do Índio; e (5) a Terra Indígena Maracaxi, situada no município de Aurora do Pará, com área de 720 hectares, cuja fase atual do procedimento consta como "Declarada", onde residem cerca de 50 pessoas. Fonte: http://ti.socioambiental.org/pt-br/\#!/pt-br/terrasindigenas $/ 3573$. Acesso em 23 de set. de 2014.

12 Conforme dados do Censo 2010 do IBGE, o Município de Santa Maria do Pará possui população de 23.026 pessoas, com área de 457,725 quilômetros quadrados. A emancipação política ocorreu em 1961, tem como limites os municípios de Igarapé-açu, Bonito, Nova Timboteua e São Domingos do Capim. Fonte: http://cidades.ibge.gov.br/xtras/perfil.php?lang=\&codmun=150660\&search=para|santa-maria-dopara|infograficos:-informacoes-completas. Acesso em 24 de set. de 2014.
} 
quilômetros de Belém, capital do estado, o Município de Santa Maria do Pará está situado na região nordeste e é cortado pela rodovia BR 316, que concentra grande fluxo de veículos e impacta diretamente a população do município, em especial os indígenas que viram a cidade avançar sobre os lugares de obtenção de alimento, de plantio, e sobre os locais considerados sagrados, como os cemitérios ${ }^{13}$, que estão hoje em áreas não acessíveis aos mesmos, inclusive sendo escavacados e remexidos por máquinas pesadas que realizam a retirada de areia nas áreas de enterramento, o que configura violência contra a memória e a tradição tembé tenetehara, desrespeitando a relação do povo com o sobrenatural, uma vez que, para os Tembé, os mortos não devem ser importunados.

Um dos locais de enterramento, denominado "cemitério velho", vem sendo remexido para retirada de areia pelo fazendeiro que adquiriu a terra. Os buracos feitos por máquina pesada estão próximos do cruzeiro central que ainda está no local. A atitude do fazendeiro desconsidera a memória e a história ${ }^{14}$ tembé tenetehara, o que violenta e viola mais uma vez a identidade deste povo, que desde o século XIX enfrenta as investidas dos regionais e as políticas homogeneizadoras do

\footnotetext{
13 O cemitério está localizado numa fazenda próxima à Vila do Dezoito, numa propriedade particular. Conforme relata Almir Vital da Silva, no período inicial da retomada da luta pelo reconhecimento étnico, fizeram um ato simbólico no antigo cemitério, que encontra-se hoje coberto por vegetação alta, ainda assim é possível identificar as sepulturas de crianças e adultos, estão visíveis e em bom estado de conservação os quatro pilares de madeira acapu que eram parte do jirau onde eram colocados os corpos para o sepultamento. O cemitério mais antigo, localizado no Prata, também está hoje em área particular, numa fazenda de criação de gado, coberto por pastagem. No local, ainda é possível identificar o cruzeiro central. Há cerca de um ano, o dono da propriedade passou a revirar a área do cemitério com maquinário para a retirada de areia. Nas várias idas a campo pudemos constatar o avanço da atividade e, juntamente com o colega Rhuan Carlos dos Santos Lopes, fizemos o registro fotográfico, elaboramos denúncia e protocolamos junto ao Instituto do Patrimônio Histórico e Artístico Nacional (IPHAN), em Belém, mas ainda não houve encaminhamentos concretos no sentido de coibir a atividade que violenta a memória e a história tembé.

${ }^{14}$ A professora Jane Felipe Beltrão foi convidada pelos Tembé Tenetehara de Santa Maria do Pará no ano de 2009 para "escrever a história do povo", uma vez que as produções sobre os mesmos é escassa. Em resposta à comunidade, a professora elaborou projetos que estão em andamento com financiamento do CNPq (Beltrão, 2012a, 2013 e 2014). Vinculados às pesquisas, outros trabalhos de mestrado e doutorado estão sendo elaborados e publicados: Beltrão (2012a e 2012b) e Beltrão e Fernandes (2014); Beltrão e Lopes (2014); Fernandes, Silva e Beltrão (2011) e Fernandes (2013). Dentre os trabalhos de pesquisa na graduação: Núcleo Colonial Indígena - documentos de Sanderly Gonçalves de Almeida (Ciências Sociais, UFPA); Indígenas em situação de violência, de Camille Gouveia Castelo Branco Barata (Ciências Sociais, UFPA); na pós-graduação as seguintes teses de doutorado estão sendo desenvolvidas: Alcoolização entre os Povos indígenas: uma proposta de ação, de Telma Eliane Garcia (PPGAUFPA); Tempos, espaços e cultura material no Prata: arqueologia Tembé/Tenetehara, de Rhuan Carlos dos Santos Lopes (PPGAUFPA); e Educação Escolar Indígena: (im)possibilidades de construção na região Nordeste do Pará, de Rosani de Fátima Fernandes.
} 
Estado brasileiro que eram parte das políticas de branqueamento delineadas e colocadas em prática no Brasil na segunda metade do século XIX e que vão embasar as políticas integracionistas e assimilacionistas para povos indígenas. Dentre as estratégias, a criação dos núcleos coloniais indígenas sob administração das missões religiosas vai ter financiamento direto do Estado com o objetivo de colocar em prática o projeto de catequização e civilização para indígenas (AMOROSO, 2001; MATTOS, 2004; PAIVA, 1982; CARNEIRO DA CUNHA, 1992; SOUZA LIMA, 1995).

Nesse sentido, o processo civilizatório para indígenas tinha como pano de fundo as políticas de branqueamento cultural com o intuito promover a mestiçagem, entendida como caminho ideal para a conformação do ideal de nação. Indígenas e negros eram, nesse contexto, considerados raças "primitivas", portanto "inferiores", precisavam ser "civilizados", na maioria dos casos via catequização, para entrarem no grande curso da história e contribuírem com o que tinham de melhor para o ideário de nação que se pretendia conformar; para tal, as diferenças culturais e linguísticas seriam suprimidas, negros, índios e brancos viveriam a eterna "democracia racial", afinal, o Brasil estava dando certo.

A principal consequência foi a implementação da política de mestiçagem, por meio do incentivo aos casamentos interétnicos entre indígenas, negros e brancos descendentes de europeus que foram enviados às partes "mais remotas do país" para desbravar, domesticar e civilizar as terras e as gentes. A contribuição dos imigrantes europeus baseava-se na formação de um povo "forte e trabalhador", com vistas ao progresso do país, não havia lugar para a indolência do indígena, nem para a malícia do negro, o que deveria prevalecer era a predisposição europeia para o trabalho e o desenvolvimento. Nasce o "mito fundador" do Brasil, com a participação e colaboração das três raças, que colocaria os índios no grande curso da historiografia oficial, que eram considerados "primitivos", povos sem história, a infância da humanidade (CARNEIRO DA CUNHA, 1992).

$O$ ideal de mestiçagem vai marcar o projeto de nação brasileira em construção e a educação escolar para povos indígenas era estrategicamente importante para "civilizar" o "selvagem"; para tanto, os 
currículos previam atividades diferenciadas para meninos e meninas, contando com aulas sobre noções de higiene, atividades agrícolas e corte e costura, tendo os rituais cívicos como base didático-pedagógica nas aldeias com o objetivo de formar "bons cidadãos" e preparar para o trabalho. O mito fundador, que seria a base para a elaboração da historiografia oficial brasileira, negou (e nega) o genocídio e o etnocídio, a escravização e o massacre que dizimou centenas de povos.

Submetidos às políticas coloniais ${ }^{15}$ de imposição religiosa, cultural e linguística financiadas pelo Estado brasileiro e colocadas em prática pelos missionários Capuchinhos da Missão do Norte, os Tembé tiveram seus filhos "sequestrados" pelos religiosos para serem catequizados e "civilizados" no Núcleo Indígena Santo Antonio do Prata, que foi projetado para controlar, disciplinar e docilizar os mesmos, porque eram considerados "selvagens". O lugar que serviu como núcleo colonial até meados da década de 20 do século passado serviu também como colônia de hansenianos, reafirmando seu papel de espaço de vigilância e controle (FOUCAULT, 2009).

No entanto, as ações do Estado não significaram o esquecimento e apagamento da identidade étnica, pois, sempre que a memória tembé é acionada nas narrativas da história pelos mais velhos, narradores por excelência, na tarefa de repassar os conhecimentos para às novas gerações pela oralidade, vem a lume a reafirmação do pertencimento étnico tembé tenetehara.

Nesse sentido, em 1999, decididos a retomar parte do território tradicional, bem como promover o fortalecimento da identidade étnica, os Tembé passaram a realizar reuniões com o objetivo de concretizar parcerias políticas para reivindicar o reconhecimento étnico. Em janeiro de 2003, fundam ${ }^{16}$ a Associação Indígena Tembé de Santa Maria do Pará

\footnotetext{
${ }^{15}$ Conforme Schwarcz (1993), os conceitos de nação, cidadania, raça, povo, entre outros, são elaborados a partir da perspectiva de cientistas que acreditavam estar definindo os rumos do país naquele momento, em que a miscigenação é tomada por espetáculo, calcada nos pressupostos teóricos evolucionistas, que vão delinear as concepções étnicas e culturais a partir do etnocentrismo. Ver também Carvalho (2001) e Colaço (2010).

$16 \mathrm{O}$ exercício do protagonismo tembé pode ser percebido, por exemplo, no relatório apresentado à Fundação Brasil de Direitos Humanos, que descreve os resultados do projeto de revitalização étnica que foi submetido e aprovado. Conforme: Tembé. 2011. Relatório apresentado à Fundação Brasil de Direitos Humanos. Santa Maria do Pará (Documento inédito).
} 
(AITESAMPA) ${ }^{17}$, que passa a ser a principal articuladora das comunidades Jeju e Areal.

Apesar das duas aldeias serem separadas geograficamente pelos limites da sede do Município de Santa Maria do Pará, os Tembé elaboram novas formas de territorialidade a partir do pertencimento étnico que os unifica em torno de objetivos em comum, mediados pela AITESAMPA, organização ${ }^{18}$ por meio da qual elaboraram estratégias coletivas de enfrentamento diante da histórica negação de direitos pelo Estado brasileiro, conforme discute Fernandes (2013) na dissertação de mestrado elaborada junto aos (com os) Tembé de Santa Maria do Pará e que problematiza a importância da Associação no fortalecimento da identidade étnica e no processo de retomada da terra. A AITESAMPA tem importância simbólica e ritual, isto porque os une internamente em torno de objetivos comuns e os representa externamente.

É a partir da Associação que a história do povo vem sendo retomada e registrada via escrita, por meio de parcerias, o que tem possibilitado a elaboração de projetos em torno do registro da memória que compõe a saga de luta tenetehara no Pará. Unificados pela formação da Comunidade Indígena Tembé Santa Maria do Pará, encaminham demandas coletivas por meio da AITESAMPA, formada pelas duas aldeias que somam atualmente o total de 103 famílias e 461 pessoas ${ }^{19}$.

A AITESAMPA é administrada por representantes das aldeias Jeju e Areal, que se alternam na presidência e nos demais cargos a cada dois anos. A Associação, para além da articulação interna, atua como interlocutora junto às instituições governamentais e não

\footnotetext{
${ }^{17}$ Sobre o processo de criação da Associação e os trabalhos desenvolvidos pela comunidade no sentido de reivindicar direitos étnicos e territoriais, consultar Fernandes, Silva e Beltrão (2011)

${ }^{18}$ Luciano (2006) define organização indígena como sendo a forma pela qual uma comunidade ou um povo indígena organiza as lutas, os trabalhos, a vida coletiva; elas podem ser tradicionais ou formais. Todos os povos têm formas de organização próprias que respondem às demandas internas. As organizações indígenas formais vêm sendo adotadas largamente pelos povos indígenas nas últimas três décadas e constituem novas formas de articulação diante de novos enfrentamentos que se apresentam, principalmente no encaminhamento de demandas referentes ao acesso e proteção das terras indígenas, às políticas específicas de saúde e educação e a direitos diferenciados. Em geral, pode-se afirmar que as associações indígenas representam as coletividades indígenas frente ao Estado nacional na defesa e promoção de direitos historicamente negligenciados. Atualmente, conforme informa Luciano (2006), são mais de 700 organizações indígenas em todo o país, coordenadas por lideranças políticas que, na maioria, buscam formação escolar como forma de qualificar as lutas. A ampliação dos números de acessos ao ensino superior tem merecido destaque nos últimos cinco anos. Para saber mais, consultar: Luciano, Oliveira e Hoffmann (2010).

${ }^{19}$ Os dados são do Censo de 2014, elaborado pela AITESAMPA.
} 
governamentais, e também protagoniza diálogos estabelecidos entre os parentes 20 tembé tenetehara das aldeias Guamá e Gurupi, na busca de apoio para o fortalecimento étnico, político e cultural. Da mesma forma, os Tembé Tenetehara entendem que os trabalhos realizados via parcerias podem ser documentos importantes na luta pela terra e pelo reconhecimento identitário.

Minha inserção entre os Tembé Tenetehara aconteceu em 2013, quando fui convidada a conhecer a comunidade por Almir Vital da Silva, que é liderança tembé e mora desde 2010 com meu irmão, Edimar Antonio Fernandes, que defendeu dissertação de mestrado no PPGD/UFPA cuja temática era a AITESAMPA e a luta por direitos. Na condição de indígena, e por residir desde 2012 com Almir em Belém, tive a possibilidade de ser recebida na comunidade como parente kaingang. O fato de ser indígena, de compartilhar vivências e experiências próximas com relação aos trabalhos que desenvolvo, me possibilitou o trânsito na cozinha de Dona Judite, que é mãe de Almir e, apesar de não sair de casa, atua como mediadora e aconselhadora nas questões que envolvem a comunidade, exercendo o papel de xamã, pela habilidade que possui de prever acontecimentos, o que é favorecido pela sensibilidade que tem no trato com as pessoas, tanto da comunidade com as quais mantém alguma relação. Sendo pessoa da cozinha de Dona Judite, em sendo mulher e educadora indígena, acionando diferentes identidades que me identificam e me aproximam de diferentes espaços e pessoas, estabeleço relações, adentro lugares permitidos, sou chamada ao compromisso de "ajudar a comunidade", ou seja, estou sujeita às formas de inclusão e exclusão, aos conflitos e tensões próprios das disputas que estão em jogo, tanto na comunidade quanto fora dela.

Nesse sentido, tenho me situado nesse campo multivocal e multifacetado, onde a pluralidade de ideias, os conflitos e as contradições estão em cena, não podendo estar ausentes de minhas

\footnotetext{
${ }^{20} \mathrm{O}$ termo indígena foi apropriado a partir da década de 70 do século passado pelos povos indígenas como identidade que une e articula as lutas em prol de objetivos em comum. Atualmente o termo parentes assume o sentido parecido, é a forma como se tratam pessoas indígenas de outras etnias, muitas com rivalidades históricas, mas que se reconhecem enquanto povos que travam cotidianamente lutas em comum. É, portanto, identidade política em torno de formas de identificação e pertencimento coletivos (LUCIANO, 2006).
} 
elaborações, que são atravessadas pelo meu pertencimento étnico, pelo fato de ser indígena mulher, de pertencer ao pequeno grupo de pósgraduandos indígenas no Estado do Pará, por estar vinculada à UFPA e também por ser acadêmica em um dos cursos em que se depositam muitas expectativas com relação à atuação e às possibilidades de contribuição com a causa tembé. Desta feita, as expectativas acabam sendo depositadas naqueles que têm uma certa experiência acumulada e por isso são vistos como importantes colaboradores.

O desfio está colocado; contribuir para a escrita da história tembé, poder participar de diversos momentos da comunidade como aliada e procurar repostas que atendam as expectativas atuais e futuras está para além da elaboração da tese, dizem respeito ao compromisso político assumido pelo fato de ser indígena e, no futuro próximo, antropóloga.

\section{Para finalizar sem encerrar ...}

No início do trabalho contextualizei minha relação pessoal com a Antropologia, também refleti acerca das contribuições da disciplina nas lutas por reconhecimento de direitos indígenas no Brasil. Procurei mostrar como o protagonismo indígena é importante para as elaborações antropológicas atuais e como a atuação dos antropólogos vem sendo resignificada e negociada pelos povos indígenas.

Concluo constatando, da mesma forma como introduzi a discussão, a necessidade de ampliação das reflexões antropológicas pelos próprios indígenas e por antropólogos não indígenas que reflitam a relação histórica da Antropologia com os mesmos. Concluo sem encerrar, afirmando a importância do estabelecimento de diálogos menos assimétricos da academia com as diferentes minorias no Brasil. A inclusão de fato somente será possível quando a descolonização técnico-científica possibilitar diálogos interculturais equitativos.

Ao final, procurei contextualizar minha presença entre os Tembé Tenetehara de Santa Maria do Pará, as implicações, dificuldades e potencialidades do trabalho que realizo, cujas discussões são ainda iniciais. Meu contato com os referenciais da Antropologia é recente, mas 
acredito que a formação, para além de um projeto pessoal, é parte de um projeto político maior, pois concebo minha presença na universidade como resultado de uma dura e árdua conquista, fruto de lutas que também tive a possibilidade de protagonizar. Por isso o desafio não é somente fazer um trabalho academicamente aceitável para a conclusão do curso, mas produzir reflexões que possam contribuir coletivamente.

Finalizo com muitas questões em aberto, algumas certamente vão me acompanhar até o final do curso, outras seguirão... e, como os Tembé que se reinventam, se refazem e seguem lutando, persisto nas reflexões e no desafio de construir uma etnografia com meus pares. Tenho, portanto, o peso da responsabilidade de construir propostas, discussões e laborações que não se encerram num trabalho final, mas que são parte de uma nova etapa em minha vida pessoal, profissional e militante.

\section{Referências bibliográficas}

ALBERT, Bruce; RAMOS, Alcida Rita. Pacificando o Branco: cosmologias do contato no Norte-Amazônico. São Paulo: UNESP, 2002.

AMOROSO, Marta Rosa. Mudança de hábito: catequese e educação para índios nos aldeamentos capuchinhos. In: SILVA, Aracy Lopes da; FERREIRA, Mariana Kawal Leal (Org.). Antropologia, História e Educação. São Paulo: Global, 2001. p. 133-156.

ARAÚJO, Ana Valéria (Org.). Povos Indígenas e a Lei dos. Brancos: o direito à diferença. Brasília: MEC/SECAD/LACED/Museu Nacional, 2006.

BARTH, Frederik. O guru, o iniciador e outras variações antropológicas. Rio de Janeiro: Contra Capa, 2000.

BELTRÃO, Jane Felipe. Indígenas e quilombolas mulheres em situação de violência: diversidade sociocultural, Direitos Humanos e Políticas Públicas na Amazônia - Chamada MCTI/CNPq/SPM-PR/MDA Nº. 32/2012, processo No. 405039/2012-3. 2012a. (Inédito).

Histórias em suspenso, os Tembé de Santa Maria: estratégias de enfrentamento de etnocídio cordial. História Hoje, Belém, v.1, p. 195-212, 2012 b. 
Reduzidos sim, vencidos nunca: identidades, histórias, memórias e patrimônio entre os Tembé Tenetehara. In: COELHO, Wilma N. B.; COELHO, Mauro C. (Org.). Trajetórias da Diversidade na Educação: formação, patrimônio e identidade. São Paulo: Livraria da Física, 2012c. p. 51-84.

Antropologias em Histórias Tembé/Tenetehara "em suspenso": pertenças ocultas e "etnogêneses" identitárias como faces de etnocídio "cordial" no rio Guamá (PA). Edital: Universal 14/2013 - Faixa C - até R\$ 120.000,00. Processo: No. 472303/2013-9. 2013. (Inédito).

Pertenças ocultas e "etnogêneses" identitárias como faces de etnocídio "cordial": Antropologias \& Histórias "em suspenso" entre os Tembé/Tenetehara no Rio Guamá. (Proposta associada à bolsa de produtividade em pesquisa (nível 1C) do CNPq). Processo: No. 303027/2013-4/CNPq. 2014. (Inédito).

BELTRÃO, Jane Felipe; FERNANDES, Rosani de Fatima. Educação escolar indígena: entre modelos históricos e diferenciados. In: MULLER, Tânia Mara Pedroso; COELHO, Wilma de Nazaré Baía (Org.). Relações Étnico-Raciais e Diversidade. Niterói: Editora da UFF/Alternativa, 2014. P. 179-200.

BELTRÃO, Jane Felipe; LOPES, Rhuan Carlos Santos. Diásporas, homogeneidades e pertenças entre os Tembé Tenetehara de Santa Maria. Aceno, Cuiabá, v. 1, n. 1, p. 123$143,2014$.

CARDOSO DE OLIVEIRA, Roberto. O Trabalho do Antropólogo. São Paulo: Editora da Unesp, 1998.

CARNEIRO DA CUNHA, Manuela. Os direitos do índio: ensaios e documentos. São Paulo: Editora Brasiliense, 1987.

História dos Índios no Brasil. São Paulo: Cia. das Letras, 1992.

Apresentação. In: ALBERT, Bruce; RAMOS, Alcida. Pacificando o branco: cosmologias do contato no norte amazônico. São Paulo: UNESP, 2002.

CARVALHO, José Jorge de. O olhar etnográfico e a voz subalterna. Horizontes Antropológicos, Porto Alegre, v. 7, n. 15, p. 107-147, 2001. Disponível em: http://www.scielo.br/scielo.php?script=sci arttext\&pid=S0104-

71832001000100005\&lng=pt\&nrm=iso. Acesso em: 12 dez. 2014.

CASTRO FARIAS, Luiz de. Antropologia: duas ciências. In: ALMEIDA, Alfredo Wagner Berno de; DOMINGUES, Heloisa Maria Bertol (Org.). Luiz de Castro Farias - Antropologia: duas ciências, notas para uma História da Antropologia no Brasil. Rio de Janeiro, CNPq/Mast, 2006. p. 15-61.

CLIFFORD, James. A experiência etnográfica: antropologia e literatura no século XX. Rio de Janeiro: Editora UFRJ, 1998. 
COLAÇO, Thais Luzia; DAMÁZIO, Eloise da Silveira Petter. Um diálogo entre o Pensamento Descolonial e a Antropologia Jurídica: elementos para o resgate dos saberes jurídicos subalternizados. Sequiência, Florianópolis, n. 61, p. 85-109, 2010. Disponível

em: http://www.egov.ufsc.br/portal/sites/default/files/um_dialogo_entre_o_pensamento_des colonial.pdf. Acesso em: 02 nov. 2014.

CORRÊA, Mariza. As reuniões brasileiras de antropologia cinquenta anos (1953-2003). Brasília: ABA, 2003.

Traficantes do simbólico \& outros ensaios sobre história da antropologia. Campinas: Ed. da UNICAMP, 2013.

FERNANDES, Edimar Antonio. Luta por direitos: estudo sobre a Associação Indígena Tembé de Santa Maria do Pará (AITESAMPA). 2013. 175 f. Dissertação (Mestrado em Direito) - Universidade Federal do Pará (Programa de Pós-Graduação em Direito). Belém. (Inédito).

FERNANDES, Edimar. Antonio; SILVA, Almir Vital da; BELTRÃO, Jane Felipe. Associação Indígena Tembé de Santa Maria do Pará (AITESAMPA) em luta por direitos étnicos. Amazônica, Belém, v. 2, p. 392-406, 2011.

FERNANDES, Florestan. "O conhecimento etnológico da realidade". In: . A investigação Etnológica no Brasil e outros ensaios. Petrópolis: Vozes, 1975. p. 116190.

FERNANDES, Rosani de Fatima. Educação Escolar Kyikatêjê: novos caminhos para aprender e ensinar. 2010. 212 f. Dissertação (Mestrado em Direito) - PPGD, UFPA, Belém, PA. Disponível em: http://www.programabolsa.org.br/pbolsa/pbolsaTeseFicha/arquivos/tese_rosani_de_fati ma_fernandes.pdf. Acesso em: 08 dez. 2014.

FOUCAULT, Michel. Vigiar e punir. Petrópolis: Vozes, 2009.

GEERTZ, Clifford. O saber local: novos ensaios em antropologia interpretativa. Petrópolis: Vozes, 1997.

GOMES, Mércio Pereira. O índio na História: o povo Tenetehara em busca da liberdade. Rio de Janeiro: Vozes, 2002.

LUCIANO, Gersem dos Santos. O índio brasileiro: o que você precisa saber sobre os povos indígenas no Brasil hoje. Brasília/Rio de Janeiro: MEC/SECAD/LACED/Museu Nacional, 2006. v. 1. Disponível em: http://www.laced.mn.ufrj.br/trilhas/. Acesso em: 30 jun. 2015.

Antropologia indígena: o caminho da descolonização e da autonomia indígena. 26 Reunião Brasileira de Antropologia. Porto Seguro: 2008. Disponível em: 
http://www.abant.org.br/conteudo/ANAIS/CD_Virtual_26_RBA/mesas_redondas/trabal hos/MR\%2018/gersem\%20baniwa.pdf. Acesso em: 20 jan. 2015.

LUCIANO, Gersem dos Santos; OLIVEIRA, Jô Cardoso; BARROSO-HOFFMANN, Maria (Org.). Olhares Indígenas Contemporâneos. Brasília: CINEP, 2010.

MATTOS, Izabel Missagia de. Civilização e revolta: os Botocudos e a catequese na Província de Minas. São Paulo: EDUSC, 2004.

MELATTI, Julio Cezar. A Antropologia no Brasil: um roteiro. Brasília: UnB, 2007. Disponível em: http://www.dan.unb.br/corpo-docente. Acesso em: 10 dez. 2014.

PACHECO DE OLIVEIRA, João; ROCHA FREIRE, Carlos Augusto da. A Presença Indígena na Formação do Brasil. Brasília: SECAD/MEC/UNESCO, 2006.

PACHECO DE OLIVEIRA, João. Pluralizando tradições etnográficas: sobre um certo mal-estar na antropologia. In: LANGDON, Esther Jean; GARNELO, Luiza. Saúde dos povos indígenas: reflexões sobre antropologia participativa. Rio de Janeiro: Contra Capa, 2004. p. 09-32.

PAIVA, José Maria de. Colonização e catequese: 1949-1600. São Paulo: Editora Cortez, 1982.

PINA CABRAL, João de. Uma história de sucesso: a antropologia brasileira vista de longe". In: TRAJANO FILHO, Wilson; LINS RIBEIRO Gustavo (Org.). O campo da antropologia no Brasil. Rio de Janeiro/Brasília: Contracapa/ABA, 2004. p. 249-265.

QUIJANO, Anibal. Colonialidade do poder, eurocentrismo e América Latina. In: A colonialidade do saber: eurocentrismo e ciências sociais. LANDER Edgardo (Org.). Perspectivas latino-americanas. Colección Sur, CLACSO, Ciudad Autónoma de Buenos Aires, Argentina, 2005. p. 227-278. Disponível em: http://bibliotecavirtual.clacso.org.ar/ar/libros/lander/pt/Quijano.rtf. Acesso em: 02 nov. 2014.

RICARDO, Carlos Alberto (Org.). Povos Indígenas no Brasil. São Paulo: CEDI, 1985. SAHLINS, Marshall. Ilhas de História. Rio de Janeiro: Zahar, 1997.

SANTOS, Silvio Coelho dos (Org.). O índio perante o direito. Florianópolis: Editora da UFSC, 1982.

Povos Indígenas e a Constituinte. Florianópolis: Movimento, 1989.

SALZANO, Francisco M. A Antropologia no Brasil: é a interdisciplinaridade possível? In: Amazônica, Belém, v. 1, n. 1, p. 12-27, 2009. Disponível em: http://www.periodicos.ufpa.br/index.php/amazonica/article/viewFile/133/271. Acesso em 15.12.2014. Acesso em: 30 jun. 2015. 
SCHWARCZ, Lilia Moritz. O espetáculo das raças: cientistas, instituições e questão racial no Brasil. São Paulo: Companhia das Letras, 1993.

SILVA, Cristhian Teófilo da. Sobre a Interpretação Antropológica: Sahlins, Obeyesekere e a racionalidade havaiana. Revista de Antropologia, São Paulo, v. 45, n. 2, p. 403-416,2002.

SOUZA LIMA, Antonio Carlos de. Um grande cerco de paz: poder tutelar, indianidade e formação do Estado no Brasil. Petrópolis/Rio de Janeiro: Vozes/Graal, 1995.

Problemas de qualificação de pessoal para novas formas de ação indigenista. In: SOUZA LIMA, Antonio Carlos de; BARROSO-HOFFMANN, Maria (Org.). Estado e Povos Indígenas: bases para uma nova política indigenista II. Rio de Janeiro: Contra Capa/LACED, 2002. p.83-95.

SPIVAK, Gayatri Chakravorty. Pode o subalterno falar? Belo Horizonte: Editora da UFMG, 2010. Disponível em: http://dx.doi.org/10.1590/S1518-70122014000100002. Acesso em: 30 jun. 2015.

TEMBÉ. Relatório apresentado à Fundação Brasil de Direitos Humanos. Santa Maria do Pará. 2011. (Inédito).

TRAJANO FILHO, Wilson; RIBEIRO, Gustavo Lins (Org.). O campo da Antropologia no Brasil. Rio de Janeiro: Contra Capa/ABA, 2004.

WAGLEY, Charles; GALVÃO, Eduardo. Os índios Tenetehara: uma cultura em transição. Rio de Janeiro: MEC/Serviço de Documentação, 1961.

Recebido em: 06/02/2015* Aprovado em: 18/05/2015* Publicado em: 30/06/2015 